\title{
High-tin bronze bowls and copper drums: Non-ferrous archaeometallurgical evidence for Khao Sek's involvement and role in regional exchange systems
}

\author{
Thomas Oliver Pryce ${ }^{\mathrm{a}, \mathrm{b}, *}$, Bérénice Bellina ${ }^{\mathrm{a}}$ \\ ${ }^{\text {a }}$ C.N.R.S., UMR 7055 Préhistoire et Technologie, Université de Paris Ouest la Défense, Nanterre, France \\ b Laboratoire Archéomatériaux et Prévision de l'Altération: LMC IRAMAT UMR5060 CNRS et NIMBE UMR3685 CEA/CNRS, Saclay, France
}

\section{Introduction}

The typological, technological and chemical analysis of copper-base artefacts has proven to be of great utility for tracing exchange networks and interaction spheres throughout late prehistoric continental and maritime Southeast Asia (e.g. Pryce et al., 2014; Hirao and Ro, 2013). Given the many similarities Khao Sek shares with Khao Sam Kaeo in terms of topography, organisation and material culture (see Bellina, this volume), we anticipated that the former would furnish a heterogeneous assemblage representing the region's numerous contacts. In this paper we will show this to be the case, and that Khao Sek's metallurgical assemblage complements current reconstructions of the Upper ThaiMalay Peninsula's Bay of Bengal and the South China Sea interaction spheres (Pryce et al., 2015; Pryce et al., 2014; Murillo-Barroso et al., 2010). The analysis of copper-base artefacts also contributes to defining the political and economic organisation of the early trading-polities that emerged during the first millennium BC.

\subsection{Corpus}

As per Khao Sam Kaeo, Khao Sek has been heavily degraded by both natural (erosion) and human (modern construction, agriculture, unauthorised excavation) processes and subsequently our excavated copper-base artefact assemblage is somewhat limited. Indeed, only one context (KK41-US2, see Bellina, in this volume) furnished any evidence for copper-base production or consumption. This consisting of a single highly vitrified ceramic with some copper staining, possibly a crucible fragment, and an amorphous corroded copper-base blob ("SEALIP/TH/ KS/1", $9 \mathrm{~g}$ ), potentially a casting splash (Fig. 1). The dearth of this material class from a relatively large Iron Age settlement would be unusual and enquiries about previous unauthorised excavations at Khao
Sek revealed that a number of interesting artefacts had in fact been unearthed.

The artefacts concerned are a large copper-base 'drum' ("SEALIP/ $\mathrm{TH} / \mathrm{KS} / 2$ ") and three copper-base bowls ("SEALIP/TH/3-5") (Fig. 2). These artefact types are widely known in Southeast Asia and would generally trigger established identification and interpretation responses on the part of regional scholars:

1. The copper-base bowl fragments, of which the $150-200 \mathrm{~mm}$ diameter rims have been preserved (Figs. 2 and 3) (probably as they are thicker and more resistant to corrosion than the base and walls) have geometric patterning comparable to bowls found at the 4th-3rd c. BC and onwards sites of Khao Sam Kaeo, Ban Don Tha Phet and Khao Jamook (Thailand), Prohear (Cambodia) and Sembiran (Bali) (Pryce et al., in press-b; Reinecke et al., 2009; Pryce et al., 2014; Calo et al., 2015; Bennett and Glover, 1992; Glover and Jahan, 2014). These bowls are produced in a 'high-tin', c. 22-23 wt. $\% \mathrm{Sn}$, bronze alloy, which is then hot-worked, quenched and decorated by incision. The motifs include naturalistic human, plant and/or animals, such as horses, deer, elephants or animals of mythical inspiration in the case of the griffin, a motive which probably arrived as a Graeco-Bactrian influence from the north-west. The style of these early decorated bowls is thought to link them to early historical Indian art, and more precisely to the Shunga period 2nd-1st BC (Glover and Jahan, 2014). Despite most of these characteristic bowls having been found in Southeast Asia, they are thought to be an Indian type, where archaeological examples have claimed dates back to c. $800 \mathrm{BC}$ and production continues using traditional techniques (Srinivasan, 2010; Srinivasan and Glover, 1995). Southeast Asian copper-base bowls with the characteristics listed above are typically interpreted as representing exchanges of

\footnotetext{
*Corresponding author at: Centre National de la Recherche Scientifique, UMR 7055 Préhistoire et Technologie, Maison René-Ginouvès, 21 Allée de l'Université, 92023 Nanterre, France.

E-mail address: topryce@gmail.com (T.O. Pryce).
} 


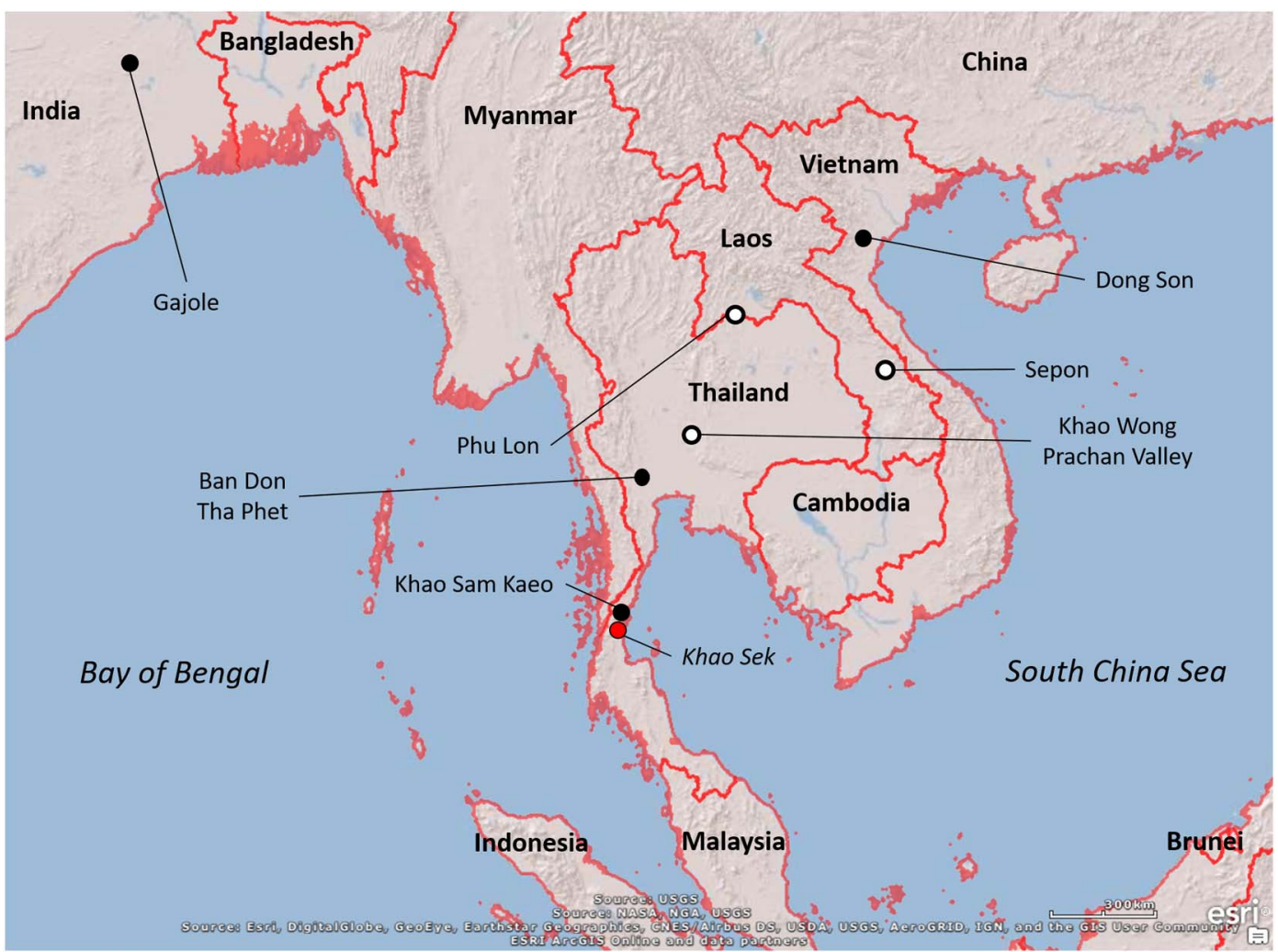

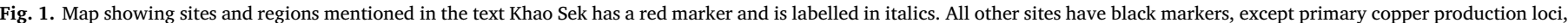
which have white markers.

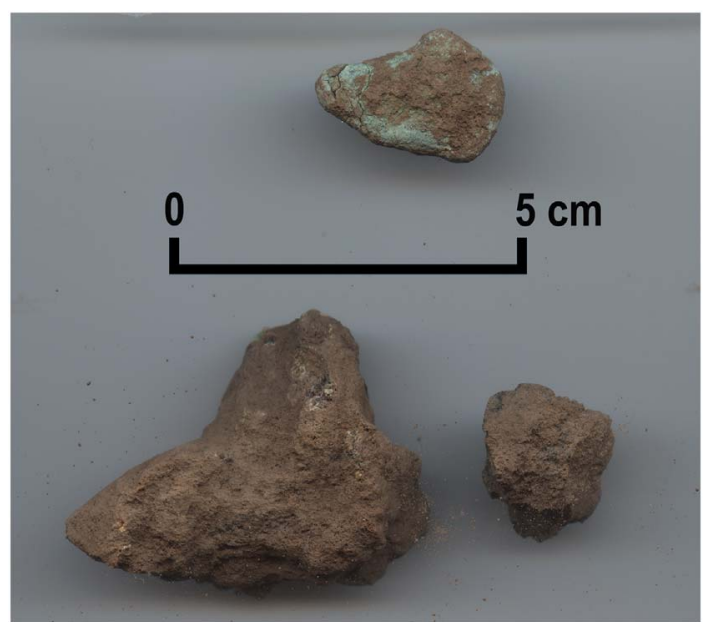

Fig. 2. Possible ceramic crucible fragments (bottom) and copper-base casting splash (SEALIP/TH/KS/1, top) artefacts.

material culture and/or people with 'India' but without any precision as to the exact locus/loci of raw material acquisition, production workshops and or distribution centres on the sub-continent. However, the analysis of crucibles and moulds from Khao Sam Kaeo revealed the onsite production of high-tin ingots using a cassiterite cementation process. These analyses thus plead for a regional production for these bowls implementing transferred Indian techniques (Murillo-Barroso et al., 2010; Pryce et al., in press-b).

2. The copper-base 'drum', of which only the c. $600 \mathrm{~mm}$ diameter putative tympanum was preserved, in fragments, has cast decoration of a radiating sun and geometric patterns that would typically be labelled 'Dongson' after their established morpho-stylistic classification (Fig. 2) (e.g. Heger, 1902; Bernet Kempers, 1988). Several hundred such artefacts have been found across continental and maritime Southeast Asia but they are widely thought to be the typeartefact of the late prehistoric north Vietnamese Dongson culture, named for the eponymous site. The identification of a 'Dongson drum' in Mainland or Island Southeast Asia commonly leads to the artefact being interpreted as representing some sort of contact with northern Vietnam; be it through the various forms of direct or indirect exchange systems (e.g. commerce, élite gifting) or even conquest (see Calo, 2014 for a recent discussion of 'Dongson drum' distribution patterning). This sort of interpretation for the Khao Sek example would fit well with previously discovered 'north Vietnamese' material, including 'drums', on the Upper Thai-Malay Peninsula (Pryce et al., in press-b).

The objective of this paper was thus to use a combined technological/geochemical approach to material culture to provide refined characterisations and interpretations of the Khao Sek copper-base assemblage. 

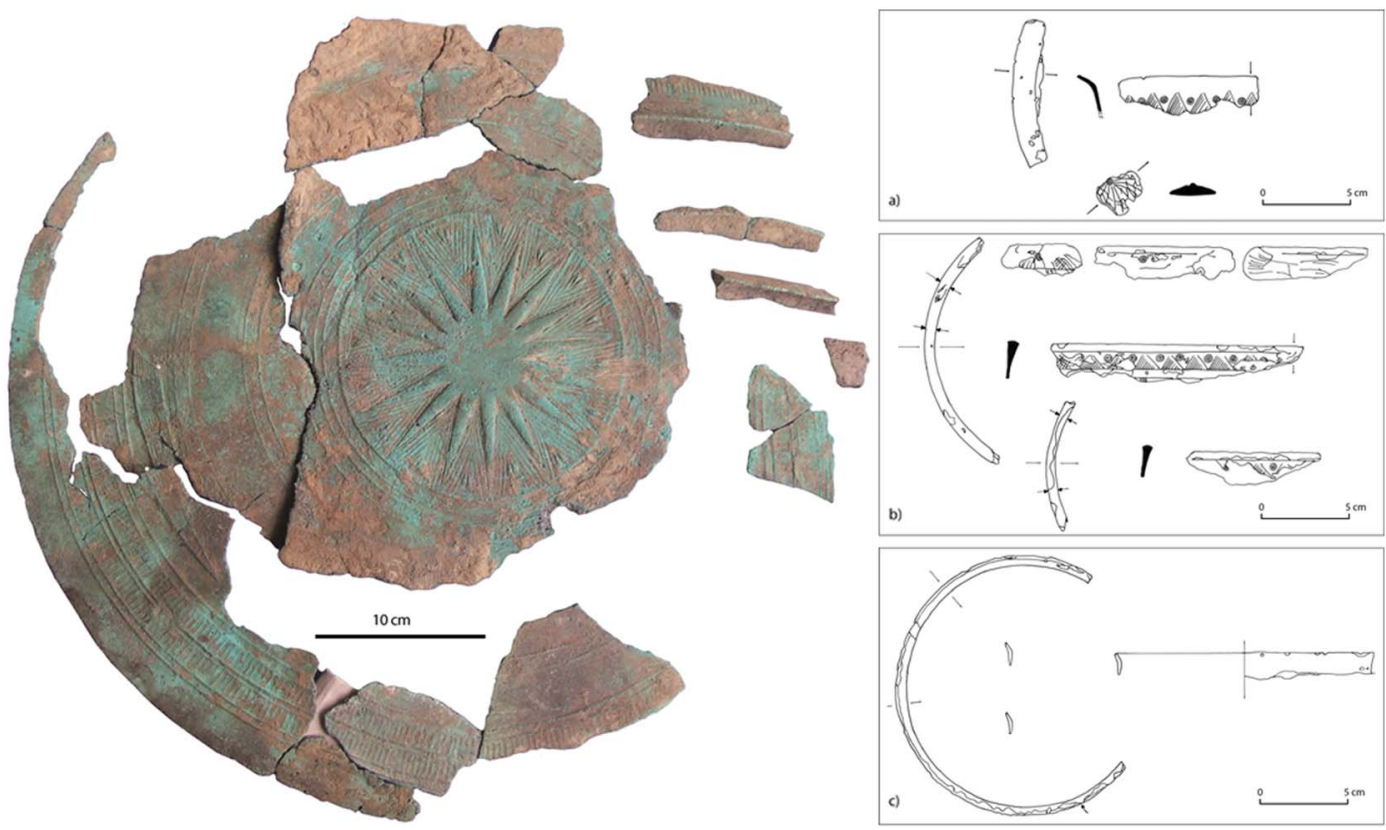

Fig. 3. Drum (SEALIP/TH/KS/2) and bowls (SEALIP/TH/KS/3-5) from Khao Sek.

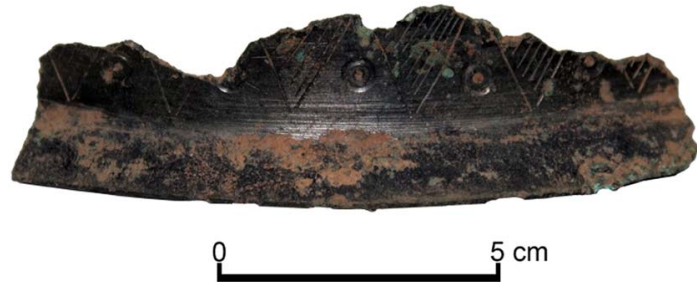

Fig. 4. Fragment of high-tin bronze bowl from Khao Sek, illustrating the shiny patina typical of this alloy, and the incised decoration often seen on wrought and quenched 'Indianising' bowls.

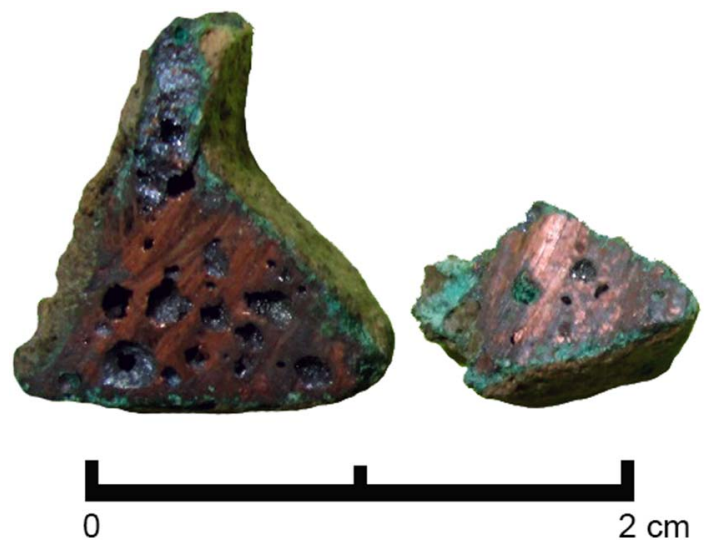

Fig. 5. Sample cut from the broken rim of the 'Dong Son' drum (SEALIP/TH/KS/2), showing pink colour and high porosity. (For interpretation of the colour reference in this figure legend the reader is referred to the web version of this article.)

\section{Methodology}

The five available metallurgical artefacts were described, photographed and drawn for their morphology and style in Thailand, as well as having 2-3 $\mathrm{m}^{3}$ of uncorroded metal sampled with a jeweller's saw for laboratory testing in Europe. These analyses consisted of metallography for improved technological information, elemental composition to confirm the alloy type, and lead isotopy to identify potential matches with the regional copper-base provenance database (Pryce et al., 2014; Hirao and Ro, 2013).

The exported sub-samples were each cut in two, with one fragment serving for optical microscopy and the other for elemental and isotopic analyses. The former were mounted in resin and polished with diamond pastes to a $0.25 \mu$ finish, before being etched with alcoholic ferric chloride to reveal their microstructures. These were examined at standardised magnifications under plane polarised light using Leica metallographic microscopes in the Wolfson Laboratories of the UCL Institute of Archaeology in London (drum) and at the Laboratoire archéomatériaux et prévision de l'altération of the Centre d'Etude Atomique in Saclay near Paris (bowls).

The second half of each sub-sample was sent to the Curt-EngelhornZentrum Archäometrie $g G m b H$ in Mannheim where their elemental composition was analysed using X-Ray Fluorescence spectrometry and their lead isotope ratios determined using Multi-Collector InductivelyCoupled Plasma Mass Spectrometry, as per the established protocols of the German laboratory and of the Southeast Asian Lead Isotope Project (Lutz and Pernicka, 1996; Niederschlag et al., 2003; Pryce et al., 2014).

The ceramic artefact was mounted and polished as described above and subjected to optical microscopy in Saclay, but not for elemental or lead isotope analysis. 


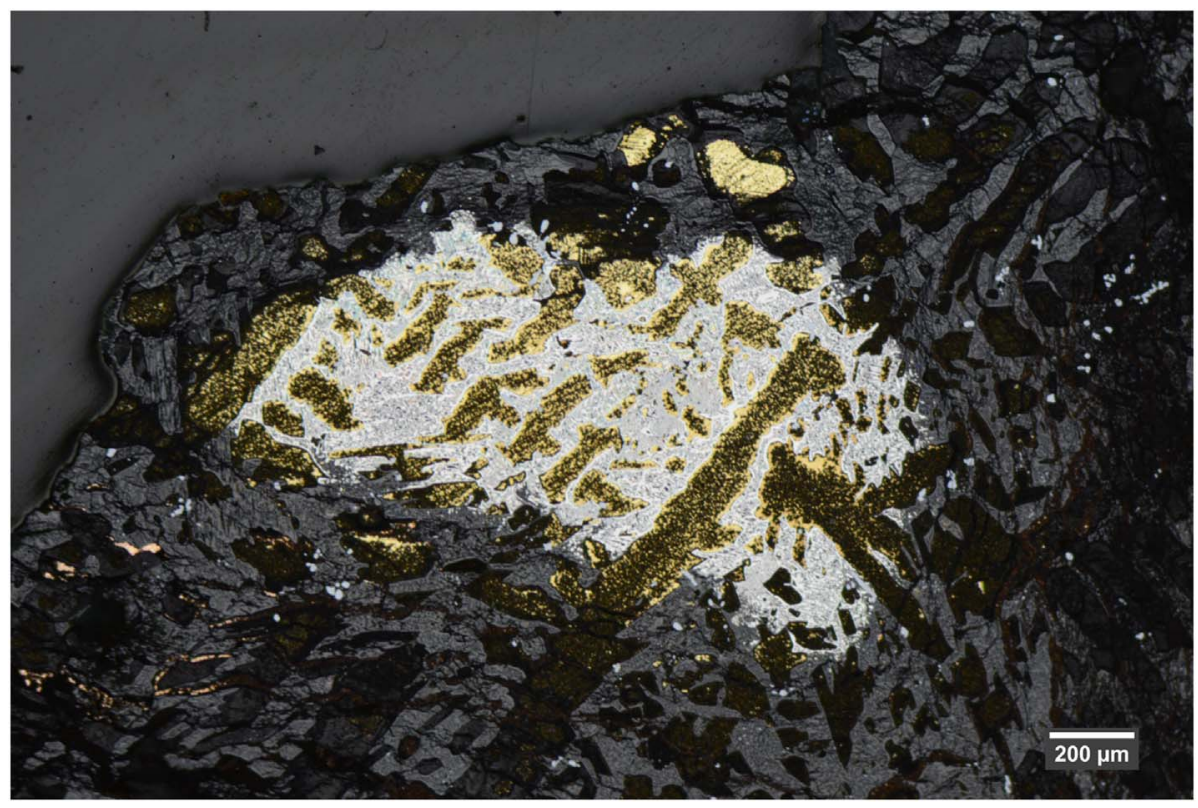

Fig. 6. Casting splash SEALIP/TH/KS/1's partially corroded dendritic microstructure, indicating the metal was left as-cast.

\section{Results}

\subsection{Macroscopic}

The Khao Sek bowl fragments bore the lustrous surface patina and bright gold colour of cut sections characteristic of high-tin bronzes, which was also suggested by the difficulty in cutting sub-samples from such hard alloys. The striations and incisions of the forming and decorating process were also visible (Fig. 4).

The corroded surfaces of the Khao Sek tympanum fragments were superficially similar to published 'Dongson drums' and those previously examined by the authors but freshly cut sections were atypical,

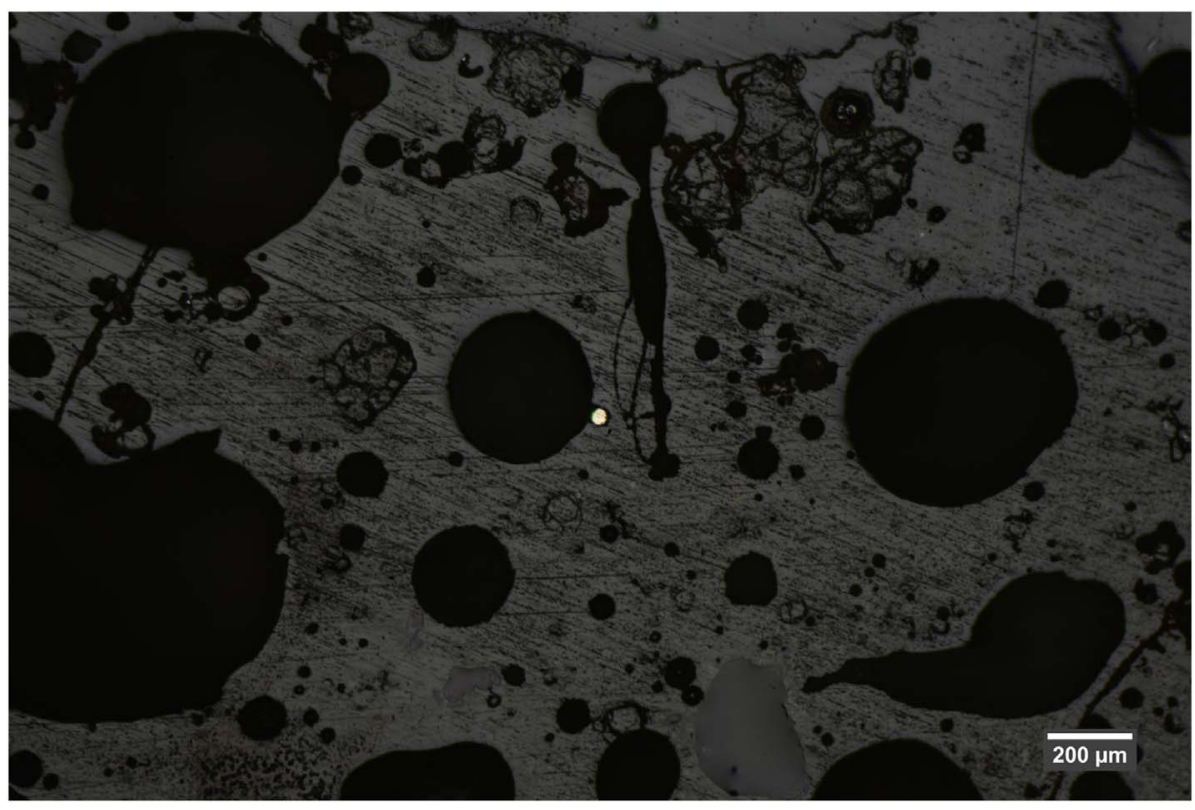

Fig. 7. Ceramic fragment microstructure under optical microscope with metallic prill in the centre of field. 


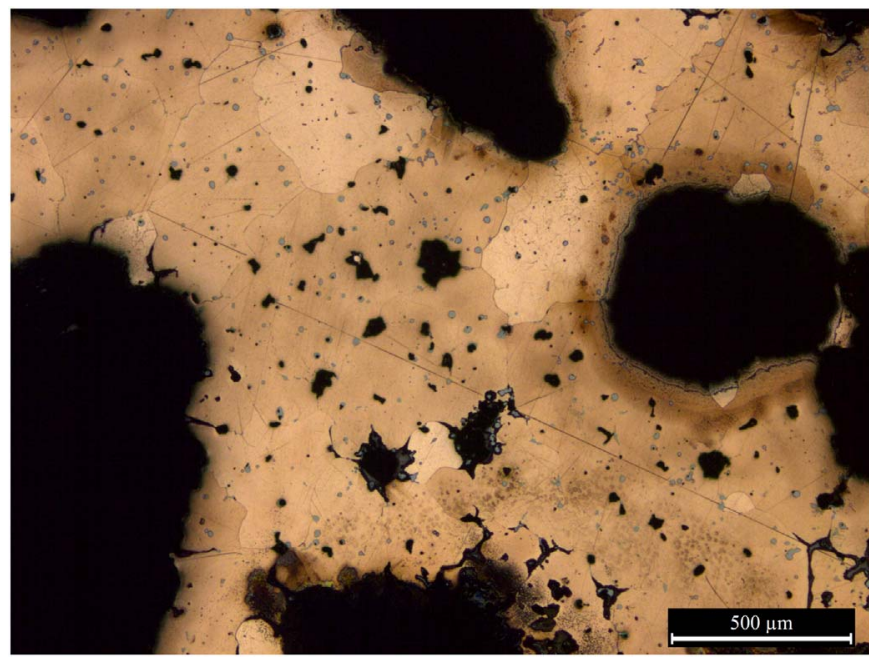

Fig. 8. 'Dong Son drum' SEALIP/TH/KS/2's equi-axed cored microstructure, courtesy of Pira Venunan. presenting extensive macro-porosity and a salmon pink tone (Fig. 5). If these artefacts were ever used as drums the degree of porosity seen in the Khao Sek example would have had an adverse impact on their sound quality, as well as on the mechanical strength of a relatively large casting. Most 'Dongson drums' are made from a leaded bronze alloy (Pryce et al., 2014), the lead and tin contributing to reduce the alloy's liquidus temperature and its gas retention, resulting in a more fluid casting with less porosity (Scott, 1991: 6). Pure copper is known for its red-pinkish tone, suggesting, before any laboratory analysis, that the Khao Sek 'drum' was lightly alloyed, if at all.

\subsection{Microscopic}

\subsubsection{Production evidence}

$\mathrm{KS} / 1$ presents a dendritic pattern (Fig. 6), commensurate with its identification as a possible casting splash. The potential technical ceramic does not have a layer of slag or oxidised metal but metallic prills are occasionally visible inside the vesicles (Fig. 7).

\subsubsection{The Khao Sek 'drum'}

The Khao Sek 'drum' presents an equi-axed cored microstructure, typical of artefacts having been cast and left to cool slowly (Fig. 8). The

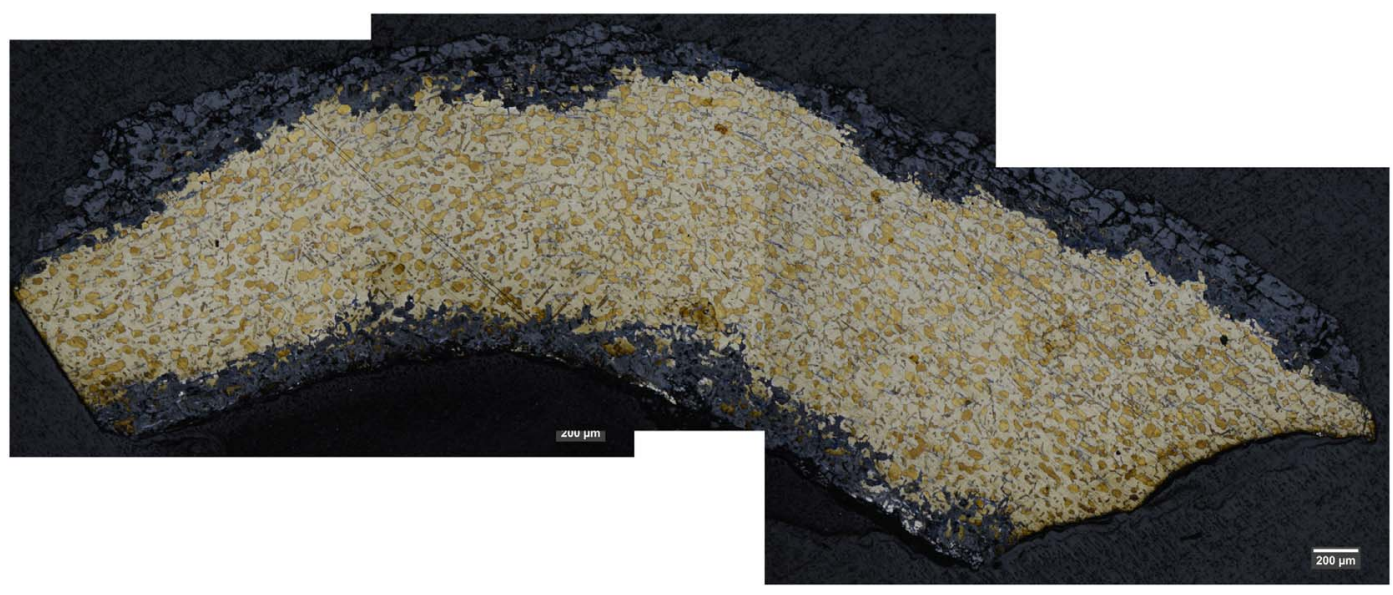

Fig. 9. Bowl SEALIP/TH/KS/3's microstructure mosaic showing characteristic martensitic texture of high-tin bronzes.

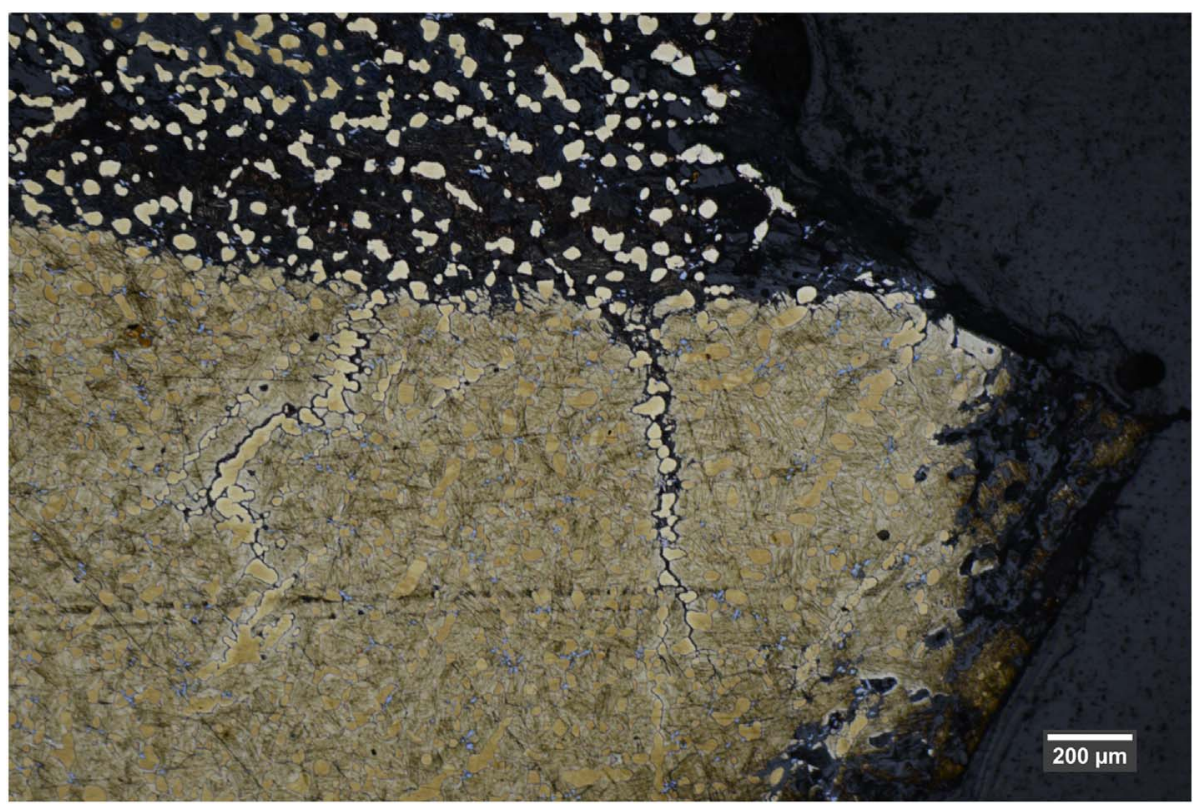

Fig. 10. Bowl SEALIP/TH/KS/4's high-tin bronze microstructure, showing equi-axed and twinned grains from hot working. 
Table 1

Context, lead isotope, elemental and alloy type data for the studied samples.

\begin{tabular}{|c|c|c|c|c|c|c|c|c|c|c|c|c|c|c|c|c|c|}
\hline Sample & Context & Object & ${ }^{208} \mathrm{~Pb} /{ }^{206} \mathrm{~Pb}$ & ${ }^{207} \mathrm{~Pb} /{ }^{206} \mathrm{~Pb}$ & ${ }^{208} \mathrm{~Pb} /{ }^{204} \mathrm{~Pb}$ & ${ }^{207} \mathrm{~Pb} /{ }^{204} \mathrm{~Pb}$ & ${ }^{206} \mathrm{~Pb} /{ }^{204} \mathrm{~Pb}$ & $\mathrm{Cu}$ & $\mathrm{Fe}$ & Co & $\mathrm{Ni}$ & $\mathrm{Zn}$ & As & $\mathrm{Ag}$ & Sn & $\mathrm{Pb}$ & Alloy \\
\hline SEALIP/TH/KS/1 & KK41/US2 & Casting splash & $2.1061 \pm 0.0001$ & $0.85318 \pm 0.00002$ & $38.919 \pm 0.004$ & $15.766 \pm 0.001$ & $18.479 \pm 0.001$ & 78.5 & bdl & bdl & 0.0 & $\mathrm{bdl}$ & 0.0 & 0.1 & 21.1 & 0.2 & hi-Sn bronze \\
\hline SEALIP/TH/KS/2 & Villager find & Drum & $2.1072 \pm 0.0001$ & $0.85600 \pm 0.00001$ & $38.693 \pm 0.006$ & $15.718 \pm 0.001$ & $18.362 \pm 0.001$ & 98.3 & 0.2 & bdl & 0.0 & bdl & 0.3 & 0.0 & 1.2 & 0.0 & copper \\
\hline SEALIP/TH/KS $/ 3$ & Villager find & Bowl & $2.0879 \pm 0.0001$ & $0.84922 \pm 0.00006$ & $38.438 \pm 0.008$ & $15.634 \pm 0.003$ & $18.41 \pm 0.003$ & 76.6 & 0.9 & 0.1 & 0.2 & 0.0 & 0.3 & 0.0 & 21.8 & 0.0 & hi-Sn bronze \\
\hline SEALIP/TH/KS/4 & Villager find & Bowl & $2.0803 \pm 0.0002$ & $0.84860 \pm 0.00006$ & $38.714 \pm 0.006$ & $15.792 \pm 0.004$ & $18.61 \pm 0.002$ & 76.0 & 0.7 & 0.1 & 0.1 & 0.0 & 0.3 & 0.0 & 22.7 & 0.0 & hi-Sn bronze \\
\hline SEALIP/TH/KS/5 & Villager find & Bowl & $1.9997 \pm 0.0002$ & $0.80722 \pm 0.00002$ & $39.260 \pm 0.010$ & $15.848 \pm 0.002$ & $19.633 \pm 0.002$ & 75.8 & 0.2 & 0.0 & 0.1 & 0.0 & 0.3 & 0.1 & 23.4 & 0.0 & hi-Sn bronze \\
\hline
\end{tabular}

porosity is extensive, with voids frequently in excess of $1 \mathrm{~mm}$. The polishing scratches, though regrettable, are symptomatic of the alloy's poor resistance to plastic deformation.

\subsubsection{The Khao Sek bowls}

The Khao Sek bowls present the classic microstructures of worked high-tin bronzes (Figs. 9-11), in which the cast object is hot-worked within a narrow temperature band and then quenched (fast cooled) to prevent the development of a brittle $\delta$-phase and retain the $\beta$-phase that

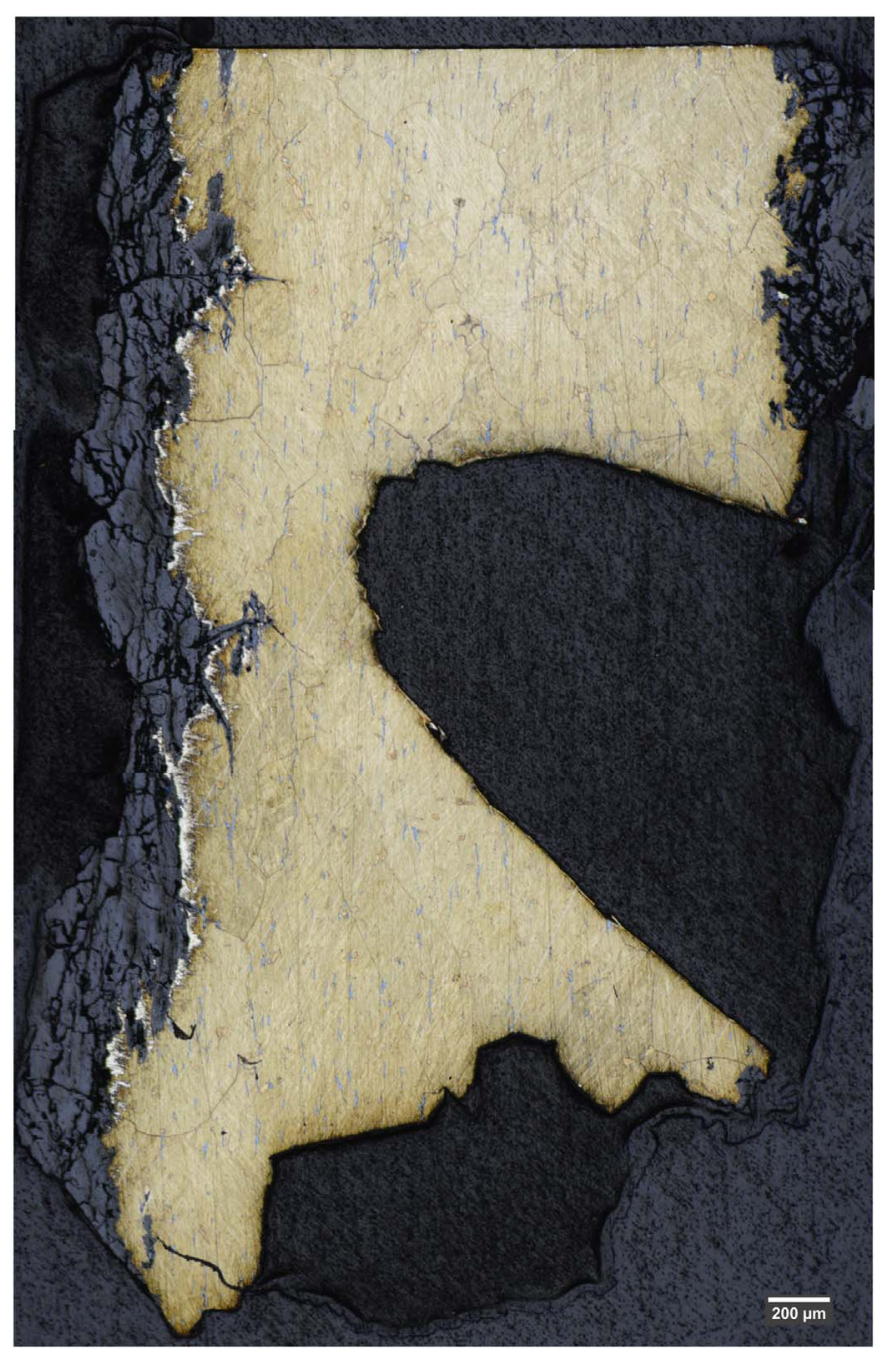

Fig. 11. Bowl SEALIP/TH/KS/5's high-tin bronze microstructure mosaic, showing equiaxed and twinned grains from hot working. forms the characteristic martensitic texture (Rajpitak, 1983; Scott, 1991; Murillo-Barroso et al., 2010; Srinivasan, 2010). In this instance the sequence of working techniques is essential for the production of such a thin-walled artefact.

\subsection{Elemental}

The XRF elemental data strongly corroborate the macro and microscopic observations; that the drum is near pure (98.3 wt. \%) copper, with tin but a minor component (1.2 wt. \%) and lead only present in trace quantities (Table 1). The casting splash and the bowls have a uniform composition of c. 76-78 wt. \% copper, c. 21-23 wt. \% tin and trace lead.

\subsection{Isotopic}

The lead isotope data show that the Khao Sek high-tin bronze casting splash and the three high-tin bronze bowl fragments, although their individual signatures are widely separated, fall within established ranges for Southeast Asian artefacts made from the same alloy (Fig. 12). The Khao Sek drum plots adjacent to the cluster of previously analysed prehistoric Southeast Asian 'Dongson' drums (Fig. 13).

\section{Discussion and conclusion}

\subsection{High-tin bronze bowls and casting evidence}

On the basis of their decoration, form, production technique, alloy and geochemical signature the three bowls from Khao Sek are wholly compatible with the current database of 'Indian' high-tin bronze bowls found in Southeast Asia (Pryce et al., 2014; Pryce et al., in press-a). The distribution of lead isotope signatures for these bowls is unusual, oriented on two axes rather than in a cluster, and cannot be fully explained at present (Fig. 12). A preliminary interpretation is that there were at least three primary production loci and that the isotopic patterning represents the mixing of these sources, i.e. some high-tin bronzes were produced with copper from multiple sources and/or melted down and recycled to make new high-tin bronzes. Furthermore, there is a radiogenic tendency to the distribution, with those samples to the upper right of Fig. 12 being more radiogenic than those to the bottom left. A copper-base alloy is usually radiogenic due to a source mineralisation containing uranium. Given the Indian attribution of high-tin bowls, a possible location for this radiogenic source is in the Singhbhum range of Jharkhand in eastern India, which has both copper and uranium reserves (Pryce et al., 2014: 291).

The Khao Sek bowls do not plot together so we can interpret they were either made with copper from multiple sources at a single workshop or at several workshops using different sources. They do however show consistency with samples from other sites: KS/3 plots near a 


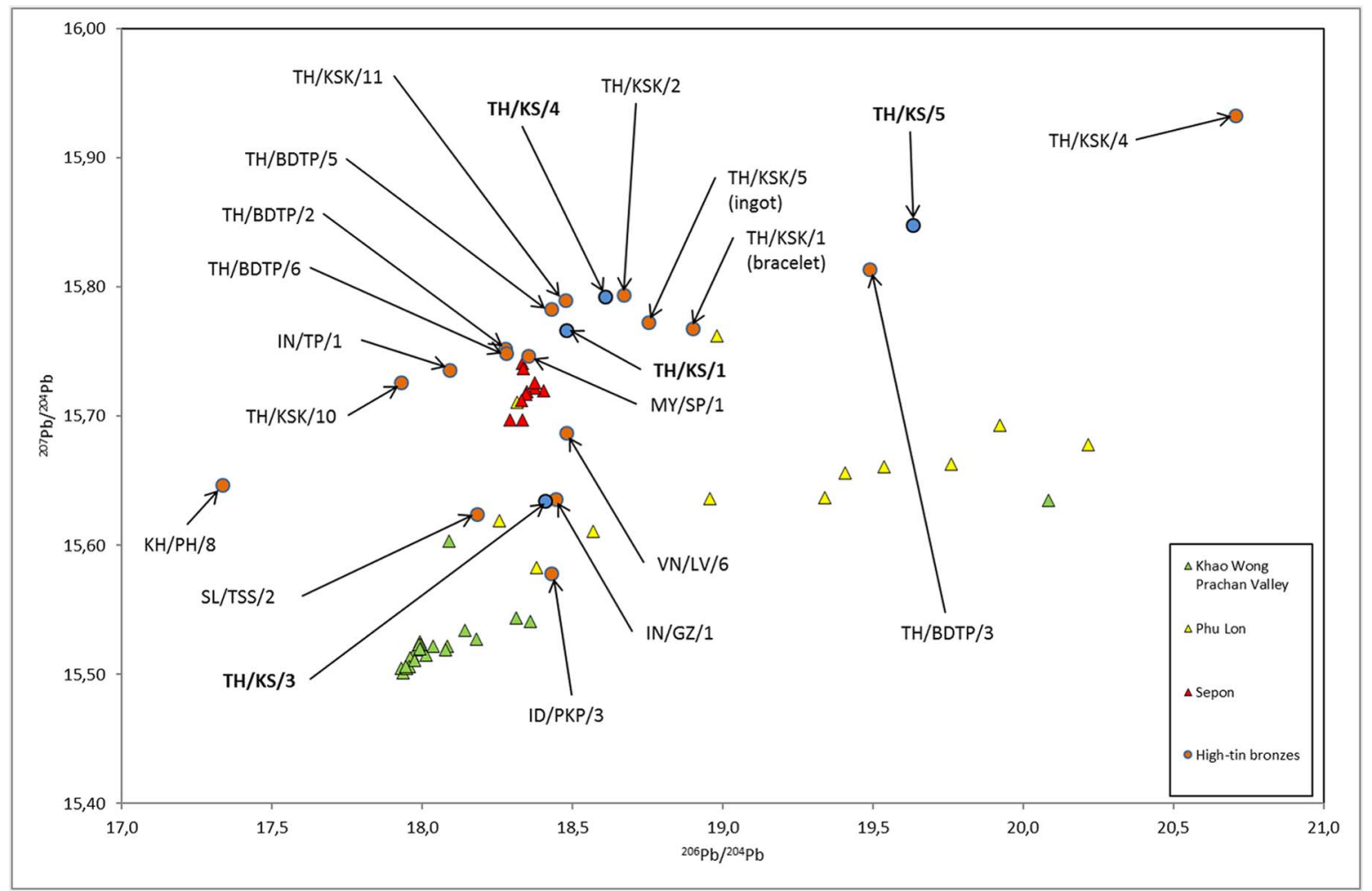

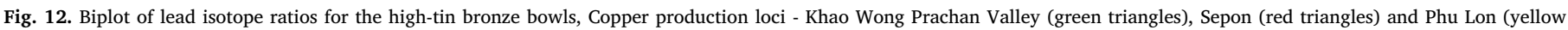
triangles). (For interpretation of the references to colour in this figure legend, the reader is referred to the web version of this article.)

Data from Pryce et al., 2014 and Pryce et al., in press-a.

sample from Gajole in West Bengal (SEALIP/IN/GJ/1), KS/4 near a bowl from Khao Sam Kaeo (SEALIP/TH/KSK/2) and KS/5 in the vicinity of a bowl from Ban Don Tha Phet (SEALIP/TH/BDTP/3). This last sample is the most radiogenic of the assemblage and thus most likely to have been made with raw materials from an area like the Singhbhum range. There is a possibility that bowl KS/4 could have been made with the same metal as represented by casting splash SEALIP/TH/KS/1 (Fig. 1), which indeed plots in the vicinity of bowls from Khao Sam Kaeo (KSK/11) and Ban Don Tha Phet (BDTP/5). More importantly it is a second instance of evidence, like the Khao Sam Kaeo ingot (KSK/5) and crucible cassiterite cementation processes (Murillo-Barroso et al., 2010; Pryce et al., in press-b), for the production of high-tin bronze alloys in prehistoric Southeast Asia; to which might be added the possibility of high-tin bronze production using Laotian copper as seen in a recently analysed bowl from central Myanmar (MY/SP/1, Pryce et al., in press-a). In summary it seems that Khao Sek was exposed to the same Bay of Bengal exchange networks as was Khao Sam Kaeo and Ban Don Tha Phet, and that these exchange networks relate to geologically diverse parts of India and Southeast Asia, some of which are yet to be identified.

\subsection{Drum}

Whilst the Khao Sek drum's form and decoration can certainly be said to suggest links between the Peninsula and northern Vietnam, its production technique, alloy and geochemical signature are inconsistent with the studied 'Dongson' corpus. Most drums are well-made from bronze or leaded bronze (Pryce et al., 2014) but the Khao Sek example is made of copper (with a minor component of tin) and has many casting faults. A tympanum of this size suggests a large drum, representing dozens of kilograms of metal, which would typically require the simultaneous heating of numerous crucibles for casting at the same time. This gives a large opportunity to affect the compositional results, as new and recycled metal from many sources could be charged to the crucibles haphazardly. However, the lead isotope data are quite clear; the drum's copper ( $98.3 \mathrm{wt} \%$ of the total) is highly compatible with the Sepon source in central Laos (Savannakhet Province) (Pryce et al., 2014; Pryce et al., 2011) (Fig. 13).

We must be very clear about what we mean here. In the absence of casting moulds, or ideally a complete foundry, we cannot know where the drum was produced. The data presented here suggest the raw material (copper) is compatible with a mineral deposit of a similar geological age and formation to that known at Sepon. The drum could have been cast in Sepon, at Khao Sek with Sepon copper, or even in northern Vietnam with Sepon copper and then transported to Khao Sek. Nevertheless, this is a very important development in understanding what the 'Dongson drum' distribution actually means historically. The Khao Sek drum presents every sign of being an ancient 'fake'. The iconography is broadly Dongsonian but the raw materials, alloy and technology are all different. The mere presence of a large copper-base drum on a Southeast Asian site cannot be interpreted as clear evidence of direct or even indirect contact between the find spot and northern Vietnam as there is substantial possibility for there having been multiple production loci introducing ideological and material revisions of the Dongson type-artefact. This potential has also been identified at the site of Non Nong Hor (Mukdahan Province) in the north-eastern region of Thailand adjacent to the Lao Savannakhet Province revealed a production site of Dong-Son-inspired drums. The site yielded clay mould fragments for casting bronze drums as well as copper ingots of a similar conical form to those coming from Sepon (Baonoed, 2016). Further analyses should be carried out to tell whether Sepon was indeed the source of these ingots.

\subsection{Summary}

The Khao Sek copper-base archaeometallurgical data reinforces and 


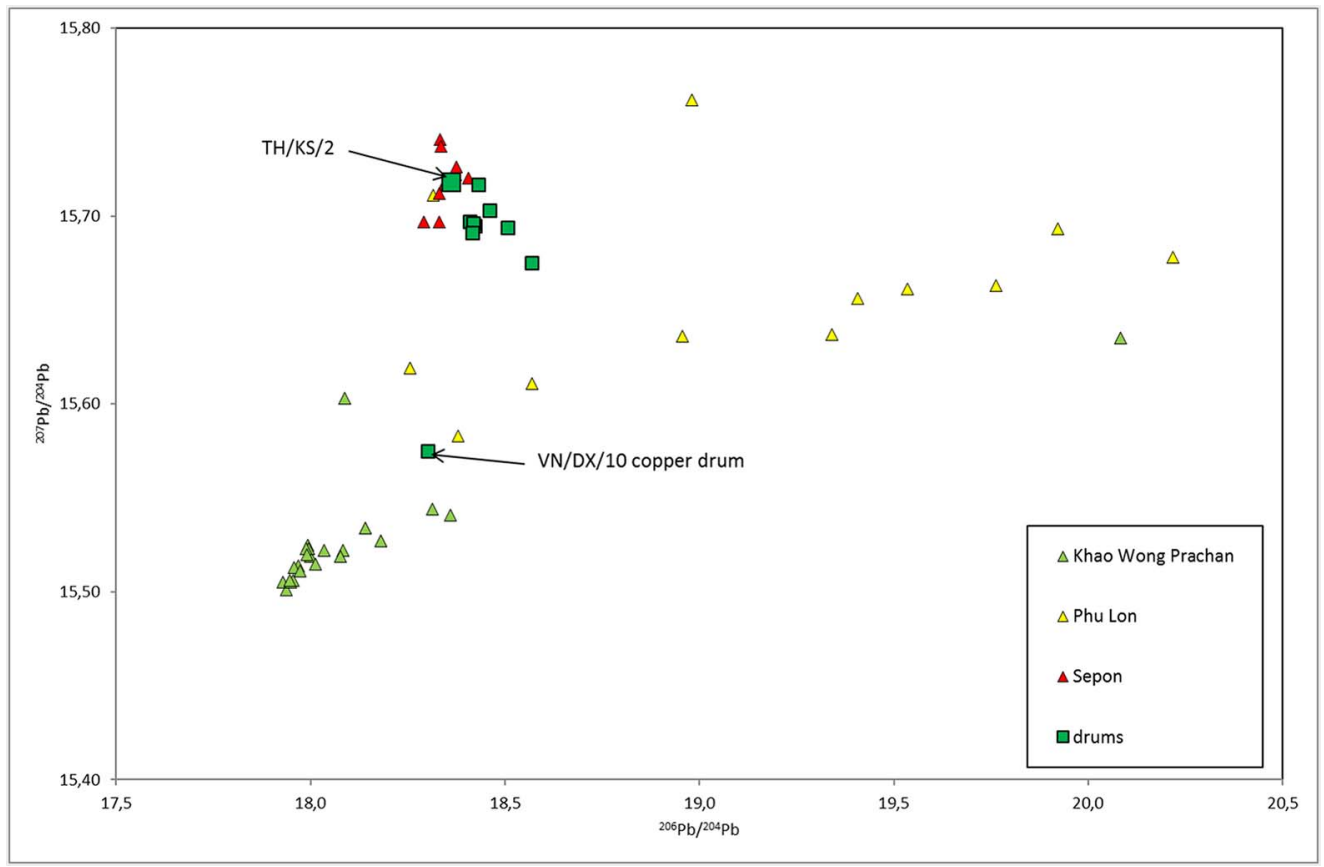

Fig. 13. Biplot of lead isotope ratios for the drum. Copper production loci - Khao Wong Prachan Valley (green triangles), Sepon (red triangles) and Phu Lon (yellow triangles). (For interpretation of the references to colour in this figure legend, the reader is referred to the web version of this article.)

Data from Pryce et al., 2014.

builds upon those of the previous programme at Khao Sam Kaeo. Although the number of artefacts is low, and preservation is not always what one might hope for, we continue to see a range of typologies, technologies and raw material sources. Concentrating on the three most important findings: firstly, a strong 'Indian' link remains with the three Khao Sek high-tin bronze bowls having internally divergent signatures that closely match the patterns derived from Indianising examples found at Khao Sam Kaeo and Ban Tha Phet, which suggests the presence of multiple primary production centres and interactions with them.

Secondly, Khao Sek has added to the evidence for the secondary production of high-tin bronzes on the Thai-Malay Peninsula, and potentially primary production from Sepon raw metal.

Thirdly, the large 'Dong Son' drum from Khao Sek may have been made with copper from Sepon in central Laos, rather than the typically speculated mineralisations in northern Vietnam. This drum was also cast with very little lead and tin, as compared to typical examples, which contributed to the very low quality of the casting. As such it appears that the Khao Sek drum is an ancient imitation/reinterpretation of northern Vietnamese material culture.

In summary, the presence of Indian-inspired high-tin bronze bowls belonging to the same Bay of Bengal networks and only one Dong Son drum which, furthermore, is an imitation - contrasting with the more numerous and probably 'genuine' Dong Son-related artefacts found at Khao Sam Kaeo (arrow heads and at least four large and two small drums) - reinforces the idea that Khao Sek was part of the same network but occupied a hierarchically inferior position to its neighbour (Bellina, this volume).

\section{Acknowledgements}

This paper was financed by the Excavation Committee of the French Ministry of Foreign Affairs and International Development. We offer our thanks also to Pira Venunan, who did the SEALIP/TH/KS/2 (drum) metallography as part of a training exercise with Pryce's former student, Harry Octavianus.

\section{References}

Baonoed, S., 2016. Non Nong Hor: The Production Site of Bronze Drum in Thailand. Abstracts of The 2nd SEAMEO SPAFA International Conference on Southeast Asian
Archaeology. 30th May - 2nd June 2016. Bangkok.

Bellina, Bérénice. Development of maritime Trade Polities and diffusion of the "South China Sea Sphere of Interaction pan-regional culture": The Khao Sek excavations and industries' studies contribution. Archaeological Research in Asia. (this volume).

Bennett, A., Glover, I.C., 1992. Decorated high-tin bronzes from Thailand's prehistory. In: Glover, I. (Ed.), Southeast Asian Archaeology 1990. Hull University: Centre for Southeast Asian Studies.

Bernet Kempers, A., 1988. The kettledrums of Southeast Asia. In: Modern Quaternary Research in Southeast Asia. 10. pp. 437-455.

Calo, A., 2014. Trails of Bronze Drums Across Early Southeast Asia: Exchange Routes and Connected Cultural Spheres. Institute of Southeast Asian Studies, Singapore.

Calo, A., Prasetyo, B., Bellwood, P., Lankton, J.W., Gratuze, B., Pryce, T.O., Reinecke, A., Leusch, V., Schenk, H., Wood, R., Bawono, R.A., Gede, I.D.K., L.K., N., Yuliati, C., Fenner, J., Reepmeyer, C., Castillo, C., Carter, A.K., 2015. Sembiran and Pacung on the north coast of Bali: a strategic crossroads for early trans-Asiatic exchange. Antiquity 89, 378-396.

Glover, I., Jahan, S.H., 2014. An early northwest Indian decorated bronze bowl from Khao Sam Kaeo. In: Revire, N., Murphy, S.A. (Eds.), Before Siam. Essays in Art and Archaeology. River Books, Bangkok.

Heger, F., 1902. Alte Metalltrommeln aus Südostasien, Leipzig.

Hirao, Y., Ro, J.-H., 2013. Chemical composition and lead isotope ratios of bronze artifacts excavated in Cambodia and Thailand. In: Yasuda, Y. (Ed.), Water Civilisation: From Yangtze to Khmer Civilisations. Springer, Tokyo.

Lutz, J., Pernicka, E., 1996. Energy dispersive X-ray fluorescence analysis of ancient copper alloys: empirical values for precision and accuracy. Archaeometry 38, 313-323.

Murillo-Barroso, M., Pryce, T.O., Bellina, B., Martinón-Torres, M., 2010. Khao Sam Kaeo an archaeometallurgical crossroads for trans-Asiatic technological styles. J. Archaeol. Sci. 37, 1761-1772.

Niederschlag, E., Pernicka, E., Seifert, T., Bartelheim, M., 2003. The determination of lead isotope ratios by multiple collector ICP-MS: a case study of Early Bronze Age artefacts and their possible relation with ore deposits of the Erzgebirge. Archaeometry 45, 61-100.

Pryce, T.O., Brauns, M., Chang, N., Pernicka, E., Pollard, M., Ramsey, C., Rehren, T., Souksavatdy, V., Sayavongkhamdy, T., 2011. Isotopic and technological variation in prehistoric primary Southeast Asian copper production. J. Archaeol. Sci. 38, 3309-3322.

Pryce, T.O., Baron, S., Bellina, B., Bellwood, P., Chang, N., Chattopadhyay, P., Dizon, E., Glover, I.C., Hamilton, E., Higham, C.F.W., Kyaw, A.A., Laychour, V., Natapintu, S., Nguyen, V., Pautreau, J.-P., Pernicka, E., Pigott, V.C., Pollard, A.M., Pottier, C., Reinecke, A., Sayavongkhamdy, T., Souksavatdy, V., White, J., 2014. More questions than answers: the Southeast Asian Lead Isotope Project 2009-2012. J. Archaeol. Sci. 42, 273-294.

Pryce, T.O., Murillo, M., Bellina, B., Martinón-Torres, M., 2015. Khao Sam Kaeo - an archaeometallurgical crossroads for trans-Asiatic technological traditions. In: Srinivasan, S., Ranganathan, S., Giumlia-Mair, A. (Eds.), Metals and Civilisations. National Institute of Advanced Studies, Bangalore.

Pryce, T.O., Htwe, K.M.M., Georgakopoulou, M., Martin, T., Vega, E., Rehren, T., Win, T.T., Win, T.T., Petchey, P., Innanchai, J., Pradier, B., 2017a. Metallurgical traditions and metal exchange networks in late prehistoric central Myanmar, c. 1000 BC to c. AD 500. Archaeol. Anthropol. Sci (in press-a).

Pryce, T.O., Murillo-Barroso, M., Biggs, L., Martinón-Torres, M., Bellina, B., 2017b. The 
metallurgical industries. In: Bellina, B. (Ed.), Khao Sam Kaeo: a Late Prehistoric City of the Upper Thai-Malay Peninsula. Ecole française d'Extrême-Orient, Paris (in press-b).

Rajpitak, W., 1983. The Development of Copper-Alloy Metallurgy in Thailand in the PreBuddhist Period With Special Reference to High-tin Bronze. (Ph.D. Thesis) Institute of Archaeology, London.

Reinecke, A., Laychour, V., Sonetra, S., 2009. The First Golden Age of Cambodia: Excavation at Prohear, Bonn, DAI-KAAK.
Scott, D.A., 1991. Metallography and Microstructure of Ancient and Historic Metals. The Getty Conservation Institute, Marina del Rey, California.

Srinivasan, S., 2010. Megalithic high-tin bronzes and peninsular India's 'living prehistory'

In: Bellina, B., Bacus, E.A., Pryce, T.O., Wisseman-Christie, J. (Eds.), 50 years of

Southeast Asian Archaeology: Essays in Honour of Ian C. Glover. River Books, Bangkok.

Srinivasan, S., Glover, I.C., 1995. Wrought and quenched, and cast high-tin bronzes in Kerala State, India. J. Hist. Metall. 29, 69-88. 